\title{
KLASIFIKASI KUALITAS MUTU JAGUNG DENGAN MENGGUNAKAN METODE DECISION TREE PADA DINAS PERTANIAN BOJONEGORO
}

\author{
Classification of corn quality using the decision tree method at the bojonegoro \\ agriculture office
}

\author{
Moch. Lutfi ${ }^{1)}$ \\ ${ }^{1}$ Program Studi Teknik Informatika, Universitas Yudharta Pasuruan \\ Email: moch.lutfi@yudharta.ac.id
}

\begin{abstract}
ABSTRAK
Jagung merupakan sumber pangan di beberapa daerah di Indonesia, selain sebagai sumber pangan manusia jagung juga dapat sebagai bahan pakan ternak. Klasifikasi mutu kualitas jagung sangat diperlukan untuk menghasilkan hasil produksi yang berkualitas. Kualitas mutu jagung ditentukan oleh attribut varietas, panjang, bentuk , warna, rasa, teknik, musim, hama, $\mathrm{PH}$ dan mutu yang digunakan sebagai proses klasifikasi kualitas mutu dengan algoritma decision tree. Hasil penelitian dibandingkan dengan tiga kriteria decision tree yaitu gain ratio, information gain dan gini index. Hasil akurasi menunjukkan bahwa nilai kriteria tertinggi sebesar $72,76 \%$ pada kriteria gini index dan nilai terendah pada kriteria gain ratio sebesar 60,67\%.

Kata Kunci: klasifikasi kualitas, mutu jagung, metode decision tree
\end{abstract}

\section{ABSTRACT}

Corn is a food source in several regions in Indonesia, in addition to being a human food source, corn can also be used as animal feed ingredients. Quality classification of corn is needed to produce quality products. The quality of corn quality is determined by the attributes of varietas, lengths, shapes, colors, flavors, techniques, seasons, pests, PH and the quality used as a classification process of quality using a decision tree algorithm. The results of the study were compared with three decision tree criteria namely gain ratio, information gain and Gini index. Accuracy results show that the highest criterion value is $72.76 \%$ in the Gini index criterion and the lowest value is the criterion gain ratio of $60.67 \%$.

Keywords: corn quality, decision tree method, quality classification

\section{PENDAHULUAN}

Jagung merupakan sumber pangan di beberapa daerah di Indonesia, selain sebagai sumber pangan manusia jagung juga dapat sebagai bahan pakan ternak (Safuan \& Hadini, 2012; Siregar \& Nugraha, 2018). Untuk meningkatkan produktivitas jagung, hal yang harus diperhatikan adalah meningkatkan produktivitas mutu kualitas produksi jagung tersebut.

Namun kenyataannya sampai saat ini yang menjadi permasalahan adalah kurangnya kualitas mutu produksi jagung. Tingginya kerusakan biji jagung di akibatkan oleh kurang baiknya dalam 
proses penanganan (Firmansyah dkk., penalaran untuk mendapatkan jawaban 2007). dari serbuah masalah (Prasetyo, 2014).

selama ini evaluasi kualitas biji Quinlan (1986) memperkenalkan dalam jagung dalam proses pengklasifikasian ID3 induksi decision tree hanya bisa masih dilakukan dengan cara manual dilakukan pada fitur yang bertipe melalui pengamatan secara langsung. kategorikal, sedangkan tipe numerik tidak Evaluasi mutu jagung dengan cara dapat digunakan. Namun quinlan pengamatan secara langsung memiliki melakukan perbaikan metode ID3 menjadi beberapa kelemahan, antara lain $\mathrm{C} 4.5$ yang dapat menangani fitur tipe membutuhkan proses waktu yang lama numerik, melakukan pemotongan, dan sehingga hasil dari proses klasifikasi mutu penurunan rule set. Algoritma C4.5 juga jagung tidak konsisten (Fitriani dkk., dapat menggunakan kriteria gain dalam 2017; Kusumaningtyas \& Asmara, 2016). Ketidak konsistenan ini disebabkan keterbatasan visual manusia, kelelahan dan adanya perbedaan persepsi tentang kualitas oleh masing-masing pengamat (Bustomi \& Dzulfikar, 2014).

Klasifikasi merupakan proses pembelajaran secara terbimbing melalui training set berdasarkan data histori (Prabowo dkk., 2018; Yaumi, 2017). Pada penelitian ini digunakan Training set dengan menggunakan metode decision tree pada dataset kualitas mutu produksi jagung pada dinas pertanian kabupaten Bojonegoro.

Decision tree merupakan algoritma yang digunakan untuk proses klasifikasi maupun prediksi melalui tahap pembentukan pohon keputusan. Pohon keputusan digunakan untuk prosedur menentukan fitur untuk pemecahan node dari akar.

Dalam penelitian ini digunakan metode decision tree untuk menentukan kualitas mutu produksi jagung dan melakuan perbandingan akurasi pada kriteria gain ratio, gini indeks, dan infomation gain.

\section{METODE PELAKSANAAN}

Penelitian ini menggunakan pendekatan kuantitatif. Metode kuantitatif bertujuan untuk mencapai pemahaman tentang bagaimana sesuatu dikonstruksi, bagaimana dibangun, atau bagaimana cara kerjanya (Berndtsson dkk., 2007). Penelitian kuantitatif pada umumnya ditekankan oleh hipotesis, yang berdasarkan rumus dan diuji secara bertahap, dengan tujuan untuk 
menunjukkan bahwa hipotesisnya benar atau salah. Oleh karena itu, salah satu upaya untuk membenarkan hipotesis, jika hipotesis tahan uji, maka akan dianggap benar sebalikan jika hipotesisnya di uji tidak tahan maka dianggap salah. Aspek pendekatan kuantitatif adalah untuk menekankan bahwa pengukuran merupakan inti dasarnya karena memberikan hubungan antara observasi dan model, teori, maupun hipotesis (Hamdi \& Bahruddin, 2015). Hasil dari penelitian dan metode kuantitatif adalah mengembangkan model, teori, dan hipotesis yang berkaitan dengan fenomena alam.
Metode yang digunakan pada penelitian ini adalah model dari eksperimen. Pada penelitian hasil eksperimen mencakup investigasi antara hubungan sebab-akibat menggunakan pengujian yang dikontrol oleh diri sendiri (Dawson, 2009). Sering kali penelitian semi eksperimental mendapatkan kendala pada tidak cukupnya akses terhadap sampel, masalah etika dan sebagainya. Eksperimen biasanya dilakukan dalam pengembangan, evaluasi dan pemecahan masalah proyek. Karena penelitian yang diakui harus mengikuti tahap prosedur (Dawson, 2009), maka pada penelitian ini dilakukan dengan mengikuti tahapan seperti Gambar 1.

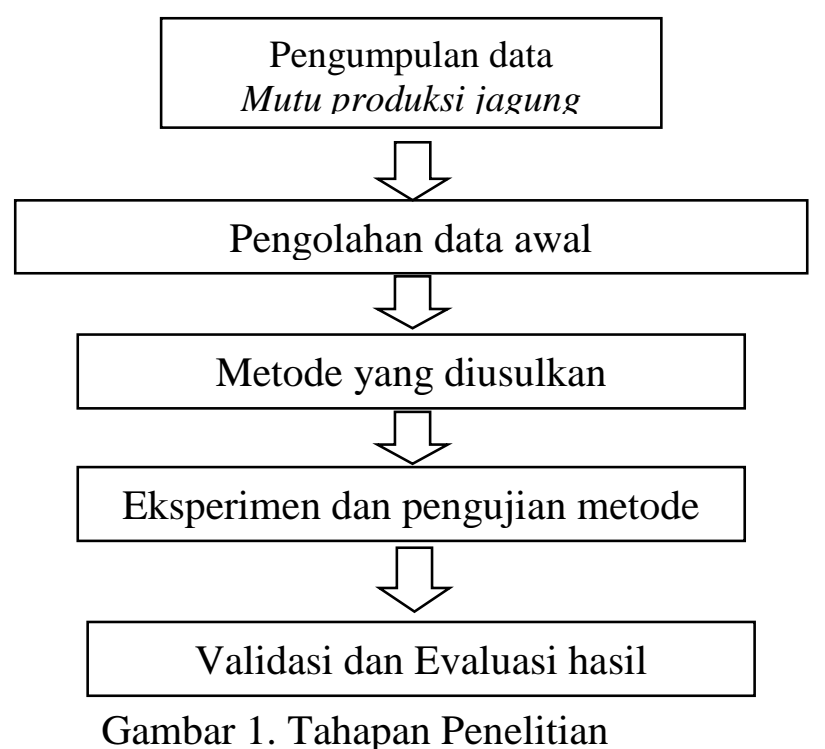

Penjelasan tahap-tahap pada sekedar melihat dan mengambil data

Gambar 1. sebagai berikut ini:

\section{Pengumpulan data}

Pengumpulan data bukan hanya sampel, tetapi harus mampu mendeskripsikan data yang ada, dan harus memiliki kontribusi terhadap 
pengetahuan. Data tersebut dapat prediksi menggunakan algoritma softmemberikan penjelasan, hubungan, computing. Pengukuran kinerja dilakukan perbandingan, prediksi, estimasi, dengan membandingkan nilai accuracy generalisasi, dan teori (Dawson, 2009). dan dibuatkan diagram untuk mengetahui

\section{Pengolahan awal data}

Data yang sudah dikumpulkan signifikasi perbedaan kinerja metode, sehingga hasil klasifikasi maupun prediksi diolah menggunakan algoritma dari masing-masing algoritma dapat softcomputing untuk mengurangi data yang tidak relevan, atau data dengan atribut yang hilang.

\section{Metode yang diusulkan}

Untuk menggambarkan alur metode yang diusulkan dan menjelaskan cara kerja metode yang diusulkan maka gambaran penelitian ini digambarkan secara skematik dan disertai dengan rumus dan penghitungan. Sedangkan metode diusulkan akan dibentuk dari data awal yang sudah proses, dan hasil pengolahan metode akan diukur dengan metode yang digunakan.

\section{Eksperimen dan pengujian metode}

Menjabarkan bagaimana eksperimen yang dilakukan hingga terbentuknya metode, serta menjelaskan cara mengujinya.

\section{Validasi dan Evaluasi hasil}

\begin{tabular}{l}
\multicolumn{2}{c}{ Validasi dilakukan } & dengan \\
mengukur hasil klasifikasi maupun \\
prediksi dibandingkan dengan data awal. \\
Evaluasi hasil dilakukan \\
mengamati hasil klasifikasi maupun
\end{tabular}

\section{Tahapan algoritma decision tree}

Tahapan membangun pohon keputusan adalah sebagai berikut:

a. Siapkan dataset produksi jagung

b. Pilih atribut sebagai akar.

c. Buat cabang untuk tiap-tiap nilai.

d. Bagi kasus pada cabang.

e. Ulangi proses untuk setiap cabang sampai semua kasus pada cabang memiliki kelas yang sama.

Untuk memilih atribut yang akan digunakan sebagai akar, didasarkan pada nilai gain tertinggi dari atribut tersebut. Untuk mendapatkan nilai gain, terlebih dahulu harus di tentukan nilai Entropinya:

\section{Entropi}

Untuk mendapatkan nilai Information gain dan gain Ratio, terlebih dahulu kita harus menghitung nilai Entropy (Madadipouya, 2015).

$\operatorname{Entropy}(S)=\sum_{j=1}^{k}-p j * \log _{2} p j$ 
Keterangan:

$\mathrm{S}=$ himpunan (dataset) kasus

$\mathrm{K}$ = banyaknya partisi $\mathrm{S}$

$\mathrm{Pj}=$ probabilitas yang di dapat dari sum

(ya) dibagi total kasus.

Sementara untuk perhitungan nilai gain digunakan.

\section{Information gain}

Setelah mendapatkan nilai Entropy langkah selanjutnya adalah perhitungan nilai Information gain dari suatu atribut (Madadipouya, 2015).

$\operatorname{Gain}(A)=\operatorname{Entropy}(S)-\sum_{i=1}^{k} \frac{\left|S_{i}\right|}{|S|} *$

$\operatorname{Entropy}\left(S_{i}\right)$

Keterangan:

$\mathrm{S}=$ himpunan kasus

$\mathrm{A}=$ atribut

$\mathrm{K}=$ jumlah partisi atribut $\mathrm{A}$

$|\mathrm{Si}|=$ jumlah kasus pada partisi ke-i

$|S|=$ jumlah kasus dalam $S$
Untuk melakukan perhitungan gain Ratio terlebih dahulu menghitung nilai Split Information (Madadipouya, 2015).

\section{Split Information $=$}

$-\sum_{i=1}^{c} \frac{S i}{S} \log 2 \frac{S i}{s}$

Keterangan:

A merupakan pecahan hasil dari $\mathrm{c}$ yang di sebit si sampai dengan sc yang memiliki nilai banyak dengan menyatakan rumus gain ratio.

$$
\text { Gain Rasio }=\frac{\operatorname{Gain}(S, A)}{\text { Split Information }(S, A)}
$$

Gini index:

$$
\operatorname{Gain}(A)=1-\sum_{k=1}^{c} P K^{2}
$$

Keterangan :

$$
\begin{aligned}
\mathrm{K}= & \text { atribut } \\
\mathrm{C}= & \text { Jumlah variabel } \mathrm{Y} \\
\mathrm{Pk}= & \text { Proporsi jumlah kelas atribut } \mathrm{K} \\
& \text { terhadap jumlah kelas } \mathrm{C} .
\end{aligned}
$$

Penerapan algoritma Decision tree sebagai klasifikasi mutu produksi tanaman jagung ditunjukkan pada Gambar 1.

\section{Gain ratio}



Gambar 2. Model penelitian yang diusulkan 
Tahapan metode dalam penelitian ini prediksi positive. False negative adalah:

1. Penerapan Metode Decision tree

merupakan jumlah record positive pada

2. Validasi menggunakan $k$-fold cross validation

dataset klasifikasi maupun prediksi negative.

Berikut adalah persamaan rumus

3. Evaluasi menggunakan Confusion Matrix

confusion matrix :

1. Akurasi (Acc): jumlah prediksi yang benar, Persamaan di bawah adalah

\section{Evaluasi dengan confution matrix}

Evaluasi menggunakan Confusion Matrix menghasilkan nilai akurasi, presisi, recall. Akurasi pada klasifikasi merupakan evaluasi hasil ketepatan data secara benar setelah dilakukan pengujian terhadap metode yang digunakan. Precision atau confidence merupakan jumlah kasus yang diprediksi negatif maupun positif. Recall atau sensitivity merupakan jumlah kasus positif yang sebenarnya diprediksi positif secara benar (Andriani, 2013; Berndtsson dkk., 2007).

Tabel 1. Confusion matrix

\begin{tabular}{ccc}
\hline \multirow{2}{*}{ Actual } & \multicolumn{2}{c}{ Predicted } \\
\cline { 2 - 3 } & - & + \\
\hline- & True negative & False positive \\
+ & False negative & True positive \\
\hline
\end{tabular}

positive merupakan jumlah record positif pada dataset klasifikasi maupun prediksi true positive. negative merupakan jumlah record negative pada dataset klasifikasi maupun prediksi true negative. False positive merupakan jumlah record positive pada dataset klasifikasi maupun 
Persamaan di bawah adalah 6. Teknik sebagai regular attribute. persamaan negative predictive value.

7. Musim sebagai regular attribute.

positive predictive value $=\frac{t n}{t n+f n}$

\section{HASIL DAN PEMBAHASAN}

\section{Pengumpulan data}

Data dalam penelitian ini adalah data tanaman jagung yang diperoleh dari database dinas pertanian Kabupaten Bojonegoro. Dataset ini terdiri dari 4961 data dengan 10 atribut, yaitu :

1. Varietas sebagai regular attribute.

2. Panjang sebagai regular attribute.

3. Bentuk sebagai regular attribute.

4. Warna sebagai regular attribute.

8. Hama sebagai regular attribute.

9. PH sebagai regular attribute.

10. Mutu sebagai label

Tabel 2. Perbandingan akurasi decision

\begin{tabular}{ccc}
\multicolumn{3}{c}{ tree } \\
\hline C4.5 & ID3 & CART \\
\hline gain raiso & information gain & gini index \\
69.67 & 72.39 & 72.76 \\
\hline
\end{tabular}

\section{Setelah dilakukan pengukuran} terhadap kriteria tahap selanjutnya dilakukan proses membandingkan akurasi dari masing-masing kriteria yang digunakan.

5. Rasa sebagai regular attribute.

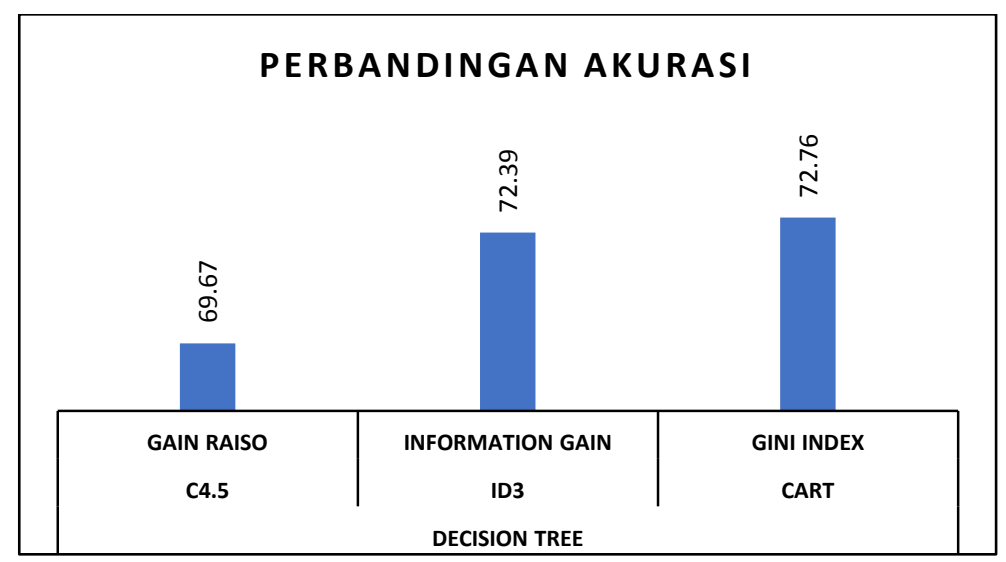

Gambar 3. grafik perbandingan akurasi decision tree

Dari grafik perbandingan diatas penggunaan kriteria dari gain ratio, information gain, dan gini index pada decision tree menunjukkan perbedaan yang signifikan, gini index menunjukkan tingkat akurasi yang tertinggi, sedangkan akurasi terendah pada kriteria gain ratio.

\section{KESIMPULAN}

Hasil penelitian dari ketiga kriteria yang sudah diimplementasikan pada decision tree yaitu gain ratio, information gain dan gini index. Hasil akurasi menunjukkan bahwa nilai kriteria tertinggi 
sebesar $72,76 \%$ pada kriteria gini index dan nilai terendah pada kriteria gain ratio sebesar $60,67 \%$.

\section{DAFTAR PUSTAKA}

Andriani, A. (2013). Sistem pendukung keputusan berbasis decision tree dalam pemberian beasiswa studi kasus: Amik BSI Yogyakarta. Seminar Nasional Teknologi Informasi Dan Komunikasi, 2013, 163-168.

Berndtsson, M., Hansson, J., Olsson, B., \& Lundell, B. (2007). Thesis projects: A guide for students in computer science and information systems. Springer Science \& Business Media.

Bustomi, M. A., \& Dzulfikar, A. Z. (2014). Analisis distribusi intensitas RGB citra digital untuk klasifikasi kualitas biji jagung menggunakan jaringan syaraf tiruan. Jurnal Fisika dan Aplikasinya, 10(3), 127-132.

Dawson, C. W. (2009). Projects in computing and information systems: A student's guide. Pearson Prentice Hall.

Firmansyah, I. U., Aqil, M., \& Sinuseng, Y. (2007). Penanganan pascapanen jagung. Puslitbang Tanaman Pangan, Badan Litbang Pertanian.

Fitriani, D., Hasbullah, R., \& Rachmat, R. (2017). Penentuan prioritas sarana pascapanen jagung untuk menurunkan kehilangan hasil dengan metode Analytical Hierarchy Process (AHP). Jurnal Penelitian Pascapanen Pertanian, 12(2), 60-69.

Hamdi, A. S., \& Bahruddin, E. (2015). Metode penelitian kuantitatif aplikasi dalam pendidikan. Deepublish.
Kusumaningtyas, S., \& Asmara, R. A. (2016). Identifikasi Kematangan Buah Tomat Berdasarkan Warna Menggunakan Metode Jaringan Syaraf Tiruan (JST). Jurnal Informatika Polinema, 2(2), 72-72.

Madadipouya, K. (2015). A new decision tree method for data mining in medicine. Advanced Computational Intelligence: An International Journal (ACII), 2(3).

Prabowo, R. Y., Rahmadwati, R., \& Mudjirahardjo, P. (2018). Klasifikasi kandungan nitrogen berdasarkan warna daun melalui color clustering menggunakan metode fuzzy c-means dan hybrid PSO k-means. Jurnal EECCIS, 12(1), 1-8.

Prasetyo, E. (2014). Data mining mengolah data menjadi informasi menggunakan matlab. Andi Offset.

Quinlan, J. R. (1986). Induction of decision trees. Machine Learning, l(1), 81-106. https://doi.org/10.1023/A:1022643 204877

Safuan, L. O., \& Hadini, H. (2012). Klasifikasi genotip jagung lokal asal kabupaten wakatobi dan kabupaten bombana berdasarkan karakter fenotipnya. J. Agroteknos, 2(3), 126-133.

Siregar, G., \& Nugraha, S. (2018). Perkembangan produksi dan konsumsi jagung di provinsi Sumatera Utara. Journal Agribusiness Sciences (JASC), 1(01). http://jurnal.umsu.ac.id/index.php/ JASc/article/view/1542

Yaumi, M. (2017). Prinsip-prinsip desain pembelajaran: Disesuaikan dengan kurikulum 2013 edisi Kedua (2 ed.). Kencana. 